\title{
SISTEMA SILVIPASTORIL NA PRODUÇÃO DE OVINOS
}

\author{
Marcelo Estremote ${ }^{1}$
}

\author{
Verônica Freitas de Paula Melo²
}

\author{
Rafael Silvio Bonilha Pinheiro ${ }^{3}$
}

\begin{abstract}
RESUMO
A preservação do meio ambiente, cada vez mais, vem sendo objeto de preocupação no mundo. No agronegócio, produtores e técnicos buscam alternativas para a pecuáriasustentável, sem agredir o meio ambiente. Uma das alternativas é o sistema silvipastoril, pois contribui para reduzir os problemas relacionados as alterações no ecossistemadecorrente do desmatamento. Contudo, a degradação das pastagens pode ser vista como um grande problema econômico e ambiental no Brasil. Esta revisão de literaturaobjetivou analisar as alternativas para a produção de ovinos de forma sustentável, utilizando a produção silvipastoril em diferentes sistemas de produção, juntamente com a recuperação de pastagens degradadas e espécies arbóreas, visando o lucro e a biodiversidade na propriedade rural.
\end{abstract}

PALAVRAS-CHAVE:Pequenos ruminantes, Sistemas de produção, Sustentável.

\section{SILVIPASTORAL SYSTEM IN SHEEP PRODUCTION}

\begin{abstract}
The preservation of the environment, increasingly, come being concern object in the world. In agribusiness, producers and technicians seek alternatives for sustainable livestock without harming the environment. One alternative is the silvopastoralsystem, it helps to reduce the problems related changes to the ecosystem resulting from deforestation. However, degradation of pastures can be seen as great hum Economic and Environmental problem in Brazil. This literature review aimed to analyze

\footnotetext{
${ }^{1}$ Programa de Pós-graduação em Ciências e Tecnologia Animal - FEIS/Unesp - Ilha Solteira/SP. Brasil. E-mail: marcelo.do@hotmail.com.

${ }^{2}$ Programa de Pós-graduação em Ciências e Tecnologia Animal - FEIS/Unesp - Ilha Solteira/SP. Brasil. E-mail: ve.fpmelo@yahoo.com.br

${ }^{3}$ Departamento de Biologia e Zootecnia - FEIS/Unesp - Ilha Solteira/SP. Brasil. E-mail:

rafaelsbp@bio.feis.unesp.br.
} 
the alternatives for the production of sustainable sheep, using silvopastoral production in different production systems, along with the recovery of degraded pastures and tree species, for profit and biodiversity on the farm.

KEYWORDS: Ruminant, Production Systems, Sustainable.

\section{SISTEMA SILVOPASTORALES EN PRODUCCIÓN OVEJAS}

\section{RESUMEN}

La preservacióndelmedio ambiente, cada vez más, ha sido motivo de preocupaciónenel mundo. Enlaagroindustria, productores y técnicos buscan alternativas para laganaderíasosteniblesindañarelmedio ambiente. Una alternativa esel sistema silvopastoril, que ayuda a reducirlos problemas de cambiosenelecosistema como resultado de ladeforestación. Sin embargo, ladegradación de los pastos puede ser visto como un problema económico y ambiental importante en Brasil. Estarevisión de la literaturadestinada a analizarlasalternativas para la producción de ovejassostenible, mediante la producciónsilvopastorilendiferentessistemas de producción, junto con la recuperación de pastosdegradados y especies de árboles, tiendocomoobjecivo el lucro y la biodiversidaden la granja.

PALABRAS CLAVE:Rumiantespequeños, Sistemas de producción, Sostenibles.

\section{INTRODUÇÃO}

Os caprinos e ovinos foram os primeiros animais a serem domesticados e estão presentes em todo o mundo,prevalecendo em sistemas agrícolas(PULINA et al., 2013). O uso de pastagens como principal fonte de alimento para os ovinos é a alternativa mais barata de alimentação dos rebanhos. Contudo, a degradação de pastagens no Brasil acarreta em grande problema econômico e ambiental.

O Brasil possuí cerca de 170 milhões de hectares de pastagens, sendo 100 milhões ocupados com pastagens cultivadas ou artificiais, as quais apresentam ampliação de sua participação ao longo dos anos em relação às pastagens nativas, em vista da maior capacidade de suporte proporcionada (QUADROS, 2006). Em decorrência, a remoção temporária ou parcial da floresta brasileira para a sua conversão em áreas de pastos e agrícolas, promovem grande impacto ambiental. Veiga et al. (2001) relataram que as pastagens proporcionam perda da biodiversidade e modificações do ecossistema devido ao desmatamento, além do 
processo de degradação e de grandes áreas de florestas secundárias originadas em áreas de pastagens abandonadas.

As práticas agrícolas e as mudanças do uso da terra devido ao desmatamento são as principais fontes de emissão de gases de efeito estufa. Aproximadamente $75 \%$ do $\mathrm{CO}_{2}$ que o Brasil emite para a atmosfera são derivados da atividade agrícola e do desmatamento, sendo apenas $25 \%$ derivados da queima de combustíveis fosseis (SANTOS, 2008).

A recuperação de áreas de pastagem degradadas é uma possibilidade para diminuir o impacto gerado pela pecuária.Oliveira et al. (2003) sugerem os sistemas silvipastoris como alternativa para contribuir com a recuperação da fertilidade do solo, aumento da biodiversidade e melhoria do uso dos recursos naturais. Muitos autores reportam ao sistema silvipastoril como fornecedor de serviços para o agronegócio, pois o mesmo disponibiliza sombra para os ovinos, fixaçãode nitrogênio no solo e nas pastagens, promove a reciclagem de nutrientes, redução daerosão do solo e proteção das nascentes; além do fornecimento de produtos como madeira,frutos, forragem, óleos, resinas, entre outros (FRANKE e FURTADO, 2001; ANDRADE et al., 2002; CARVALHO et al., 2002).

O sistema silvipastorilimplantado na ovinocultura tem a finalidade de explorarespécies arbóreas, ovinos e pastagens em uma mesma área física. Na qual, árvores e/ou arbustos, pela influência que exercem no processo de ciclagem de nutrientes e no aproveitamento da energia solar, são considerados os elementos estruturais básicos e a chave para a estabilidade do sistema.

Restle et al. (2007) citam o sistema silvipastoril como um método eficiente para criação de pequenos ruminantes, trazendo vantagens aos ovinos e ao ecossistema, proporcionando um melhor conforto térmico aos animais. Os autores ainda comentam que isto pode refletir em melhora no desempenho tanto na produção de leite, como de carne e lã, aumento do peso do cordeiro ao desmame, diminuir períodos de recria e terminação de machos, além de reduzir a idade de puberdade das fêmeas e aumento da vida produtiva. 


\section{OBJETIVO}

Esta revisão de literatura objetivou analisar as alternativas para a produção de ovinos de forma sustentável, utilizando o sistema de produção silvipastoril em diferentes sistemas de produção, juntamente com a recuperação de pastagens degradadas e espécies arbóreas, visando o lucro e a biodiversidade na propriedade rural.

\section{DESENVOLVIMENTO}

\subsection{EFEITOS NO SOLO COM SISTEMA SILVIPASTORIL}

A implantação de árvores em áreas de pastagens reduz a perda de nutrientes por lixiviação ou erosão e aumenta a disponibilidade de matéria orgânica no solo. O solo sob a copa das árvores apresenta melhorfertilidade, por isso possibilitamaior degradação da matéria orgânica e maior liberação de nitrogênio e minerais (WILSON,1998). Contudo, os efeitos esperados são de longo prazo pois dependem,principalmente, do crescimento de árvores e dos processos de decomposição.

As espécies arbóreas, podem atuar no controle da erosão eólica e hídrica (HOUGHTON, 1984), atuando no sistema como quebra ventos, reduzindo a velocidade dos ventos e auxiliando na diminuição das perdas da umidade do solo. $O$ controle da erosão hídrica pelas árvores é obtido devido à redução na intensidade da chuva que chega ao solo; ao aumento na infiltração de água, à manutenção de teor adequado de matéria orgânica na superfície e ao efeito agregador das partículas do solo (HOUGHTON, 1984).

Em pastagens, a introdução de árvores tem como objetivo o aumento de nutrientes no solo, bem como a melhoria na ciclagem destes, através da absorção dos elementos pelas raízes das árvores nas camadas mais profundas do solo (WADT et al., 2003). A posterior deposição de nutrientes na camada superficial, por meio da decomposição de galhos, folhas e raízes incorporadas (OLIVEIRA; LEITE; CASTRO, 2005) também são fundamentais para o aumento de nutrientes no solo.

Além disso, a introdução de árvores no sistema proporciona redução 
considerável na acidez do solo, principalmente na camada mais superficial. De acordo com Nascimento et al., (2003), esse efeito é provavelmente devido ao maior retorno dos resíduos das plantas ao solo e maior concentração de raízes no perfil favorecendo, assim, maior absorção e ciclagem de nutrientes.

A participação das ovelhas no sistemacontribui significativamente para a fertilização do solo, através do lançamento diário dos dejetos sólidos e líquidos (fezes e urina), onde $1000 \mathrm{~g}$ de esterco fresco de ovinos e caprinos contém 2,07 g/kg de $\mathrm{N} ; 1,03 \mathrm{~g} / \mathrm{kg}$ de $\mathrm{P}$ e $0,52 \mathrm{~g} / \mathrm{kg}$ de $\mathrm{K}$, além da matéria orgânica e micronutrientes; já a urina destes animais, estima-se esta mesma quantidade em $19 \mathrm{~g} / \mathrm{kg}$ de $\mathrm{N}$ e $23 \mathrm{~g} / \mathrm{kg}$ de K (FALESI; BAENA, 1999).

O material orgânico produzido pelas ovelhas é decomposto por microrganismos presentes no solo. Com o aumento da idade da pastagem, que se encontra no sistema em equilíbrio sustentável, o solo apresenta uma condição de equilíbrio dinâmico onde as perdas anuais de matéria orgânica são balanceadas pelas entradas no decorrer do sistema. Este processo é conhecido como reciclagem e no caso do carbono é definido como o fluxo através do conteúdo total do carbono a uma dada amostra de solo (SANTOS, 2008).

\subsection{SOMBREAMENTO COM SISTEMA SILVIPASTORIL NO CONFORTO TÉRMICO ANIMAL}

A atividade agropecuária no Brasil é de extrema importância econômica e destaca-se na produção de pequenos ruminantes principalmente na região Nordeste do país. $O$ nordeste brasileiroapresenta peculiaridades climáticas que dificultam 0 processo produtivo, muitas vezes colocando os animaisem condições de desconforto térmico.

Alguns fatores ambientais como, temperatura, umidade, movimentação do ar e radiação solar, quando atingem valores superiores ao conforto térmico dos ovinos e caprinos, podem exercer influência negativa sobre o desempenho destes animais, comprometendo a produção de leite, ganho de peso, crescimento e a reprodução, em decorrência de um processo conhecido como estresse calórico (PACIULLO et 
al., 2014).

De acordo com Neiva et al. (2004) a interação animal x ambiente deve ser considerada quando se busca maior eficiência na exploração pecuária, pois as diferentes respostas do animal às peculiaridades de cada região são determinantes no sucesso da atividade produtiva. Sendo assim, a correta identificação dos fatores que influem na vida produtiva do animal, como o estresse imposto pelas flutuações estacionais do meio-ambiente, permitem ajustes nas práticas de manejo dos sistemas de produção (NEIVA et al., 2004).

Beede eCollier (1986) comentam que o estresse térmico pode acarretar alguns prejuízos aos animais como maiores taxas de respiração, aumento no consumo de água, menor apetite e considerável perda de sais minerais como potássio e sódio. No caso dos machos, o estresse calórico pode ocasionar redução do volume seminal por ejaculação e aumento do número de espermatozoides anormais (defeituosos e mortos).

No sistemasilvipastoril, o ambiente gerado pela implantação de espécies arbóreas, confere melhores condições de conforto térmico para os ovinos, principalmente em regiões de clima tropical e subtropical, onde o estresse térmico é constante. A procura por sombra durante o calor e estiagem são maiores, e com isso é indicado o uso de espécies arbóreas com copas globosas e densas (FALESI et al., 2012). A oferta de sombra neste sistema de produção é capaz de reduzir em mais de $30 \%$ a carga de calor radiante, em climas quentes (BLACKSHAW; BLACKSHAW, 1994).

Carvalho et al. (2011) relataram que sistemas de integração lavourapecuária-floresta (ILPF), com eucalipto, apresentaram menor temperatura e velocidade do vento, e maior umidade relativa do ar, em relação a sistemas integrados sem árvores, indicando melhores condições microclimáticas para animais em pastejo.

\subsection{SOMBREAMENTO SOBRE A FORRAGEIRA}

Alguns trabalhos mostram um estímulo da sombra ao crescimento da parte 
aérea, e outras a ausência de efeito prejudicial ao crescimento, mas há vários trabalhos que mostram a redução no crescimento de forrageiras pelo efeito da redução da radiação solar (CASTRO et al. 1997).

Gramíneas forrageiras são mais sensíveis ao sombreamento na fase de estabelecimento do que na fase produtiva, sendo que, para níveis de sombreamento de $30 \%$ a $50 \%$, as gramíneas: Urochloabrizantha(cv. Marandu, cv. Xaraés e cv. Piatã), U. decumbens(cv. Basilisk) e Panicummaximum(cv. Aruana, cv. Mombaça, cv. Tanzânia e cv. Massai) são consideradas tolerantes e com produção satisfatória em sistemas silvipastoris (ALMEIDA et al., 2014).

O manejo da pastagem em sistemas silvipastoris deve ser mais afinado, pois ocorre um grau de competição entre as forrageiras e espécies arbóreas mais elevadas do que em monocultivocom sol em abundância, sendo que, nestes sistemas, o efeito do superpastejo tende a ser elevado. Assim, o monitoramento correto da altura de pastejo de cada espécie/cultivar deve ser acompanhado, para permitir maior acúmulo de reservas e favorecer a rebrota (ALMEIDA et al., 2014).

Em relação ao benefício do sistema silvipastoril no desenvolvimento da pastagem, alguns estudos têm mostrado um aumento na biomassa acumulada sob sombra natural e artificial (SAMARAKOON et al. 1990). Outros estudos mostram a eficiência do uso da radiação de gramíneas sob sombra é maior que obtida em sol pleno (CRUZ et al., 1995).

Conforme Carvalho (1998) o efeito do sombreamento afirma que as alterações mais consistentes que têm sido observadas nas forrageiras são 0 aumento na concentração de proteína bruta e a redução nos teores de carboidratos não estruturais totais.

Efeitos sobre a digestibilidade, conteúdo da parede celular e consumo voluntário de forragem são variáveis, e algumas vezes menores do que as variações entre espécies forrageiras. As principais condições para se obter benefícios do sombreamento sobre as forrageiras, com ênfase nas gramíneas, são o uso de sombreamento moderado e de espécies tolerantes a essa condição (CARVALHO, 1998).

Resultados obtidos por Paciullo et al. (2008), evidenciaram um aumento médio de $22 \%$ de nitrogênio e $17 \%$ de potássio nas folhas verdes 
de Urochloadecumbens situadas embaixo das áreas de influência das copas das árvores. Também se observou resultados positivos obtidos com a forrageira Urochloabrizantha, com aumento médio de 38\% de nitrogênio e 35\% de potássio. Isto implica que as gramíneas que se desenvolveram sob as árvores cultivadas são mais nutritivas para os animais em pastejo (CARVALHO et.al. 1999), que podem refletir no aumento da produção de carne, leite e lã.

Santos e Santos (2010) observaram que ovinos mantidos no sistema silvipastoril obtiveram média do ganho depeso entre 180 e 150 g/animal/dia, enquanto que, napastagem de capim Tifton 85 as médias foram 200 e $120 \mathrm{~g} / \mathrm{animal} / \mathrm{dia}$, respectivamente, durante o período daschuvas e deestiagem. Além disso, os ganhos de peso anuais dos ovinos variaram de 24,5 e 22,1 kg/animal, respectivamente, para os animais mantidos em sistema silvipastoril e em pastagem de capim Tifton 85. Santos e Santos (2010) comentam que a diferença no ganho de peso alcançada entreos tratamentos avaliados durante a estiagem, foidevido ao melhor conforto de sombreamentoproporcionado pelo Eucaliptusgrandis e da diversidadede forrageiras e leguminosas que os animais do sistemasilvipastoril tiveram acesso.

\section{CONCLUSÃO}

A produção de ovinos em sistemas silvipastoris pode ser uma alternativa economicamente viável a longo prazo. A presença de espécies arbóreas em sistemas pecuários pode ser capaz de proporcionar um microclima mais favorável aos animais e reduzir o efeito do estresse térmico, com potencial melhoria dos índices produtivos e reprodutivos. Além disso, o sistema silvipastoril pode auxiliar nas propriedades físicas e químicas do solo e da planta forrageira, beneficiando a atividade agropecuária e o meio ambiente.

\section{REFERENCIAS}

ALMEIDA, Roberto Giolo et al. Sistemas Silvipastoris: produção animal com benefícios ambientais: Produção animal novas diretrizes. In: CONGRESSO NORDESTINO DE PRODUÇÃO ANIMAL, 9, 2014, Ilheus - Ba. Anais... Ilheus - Ba: Cnpa, 2014. 
ANDRADE, Carlos Mauricio Soares et al. Árvores de baginha (Stryphnodendron guianense (Aubl.). Benth.) em Ecossistemas de Pastagens Cultivadas na Amazônia Ocidental. R. Bras. Zootec., v.31, n.2, p.574-582, 2002.

BEEDE, DavidK.; COLLIER, RobertJ. Potencialnutricional strategies for intensively managed calttle during thermal stress. J. Anim. Sci., Champaign, v.62, n.2, p.543-554, 1986.

BLACKSHAW, J. K.; BLACKSHAW, A. W. Heat stress in cattle and the effect of shade on production and behaviour: a review. Australian Journal of Experimental Agriculture, v.34, n.2, p.285-295, 1994.

CARVALHO, Margarida Mesquita. Efeito do sombreamento na produtividade e na qualidade da forragem em pastagens. In: II Congresso Brasileiro de Biometeorologia, 1998, Goiânia. Anais... Goiânia, 1998. p. 99-117.

CARVALHO, Margarida Mesquita; FREITAS, Vicente de Paula; XAVIER, Deise Ferreira. Comportamento de cinco leguminosas arbóreas exóticas em pastagem formada em Latossolo Vermelho-Amarelo de baixa fertilidade. R.Árv., Viçosa, v. 23, n. 2, p. 187-192, 1999.

CARVALHO, Margarida Mesquita; XAVIER, Deise Ferreira; ALVIM, Maurílio José. Características de algumas leguminosas arbóreas adequadas para associação com pastagens. Juiz de Fora: Embrapa Gado de Leite, 2002. (Embrapa Circular técnica, 64).

CARVALHO, Pedro Henrique Vilela et al. Características microclimáticas no inverno em sistemas de integração lavoura-pecuária-floresta (iLPF). In: JORNADA CIENTÍFICA DA EMBRAPA GADO DE CORTE, 7, 2011. Anais... Campo Grande: Embrapa Gado de Corte, 2011. p. 40-41. (Embrapa Gado de Corte. Documentos, 186).

CASTRO, Carlos Renato Tavares et al. Produção forrageira e alterações morfológicas em gramíneas cultivadas sob luminosidade reduzida. In: XXXIV Reunião Anual da Sociedade Brasileira de Zootecnia, 1997, Juiz de Fora. Anais... Juiz de Fora, 1997. Forragicultura, v.2, p.338-340.

CRUZ, Pablo et al. Effects of shade on growth, nitrogen content and $\mathrm{CO} 2$ leaf assimilation in a tropical perennial grass. In: SINOQUET H.; CRUZ, P. (Ed.) Ecophysiology of tropical intercropping. Versailles: INRA Editions, p.285-293, 1995.

FRANKE, Idésio Luís; FURTADO, Sérvulo Casas. Sistemas silvipastoris: fundamentos e aplicabilidade. Rio Branco: Embrapa Acre, 2001. 51p. (Embrapa Acre. Documentos; 74). 
FALESI, Italo Claudio; BAENA, AntonioRonaldo Camacho.Mogno-africano Khayaivorensis A. Chev. em sistema silvipastoril com leguminosa e revestimento natural do solo. Belém: Embrapa Amazônia Oriental, 1999. 52p. (Embrapa Amazônia Oriental, Documentos, 4.)

FALESI, Ítalo Claudio et al. Sistema Silvipastoril Sustentável com Ovinos em Pastejo Rotacionado Intensivo. $1^{\mathrm{a}}$ ed. Belém: Edufra, 2012. P.

HOUGHTON, D. Trees and erosion control. Queensland Agricultural Journal, Brisbane, v. 110, n. 1, p. 9-12, 1984.

NASCIMENTO, João T. et al. Efeito de leguminosas nas características químicas e matéria orgânica de um solo degradado. R. Bras. Eng. Agr.Amb.,v.7, p.457-462, 2003.

NEIVA, José NeumanMiranda et al. Efeito do Estresse Climático sobre os Parâmetros Produtivos e Fisiológicos de Ovinos Santa Inês Mantidos em Confinamento na Região Litorânea do Nordeste do Brasil. R. Bras. Zootec., v.33, n.3, p.668-678, 2004.

OLIVEIRA, TadárioKamel et al. Sugestões para implantação de sistemas silvipastoris. Rio Branco: Embrapa Acre, 2003. 28p. (Documentos,84).

OLIVEIRA, Maria Elizabete; LEITE, Laercio Leonel; CASTRO, LuisHernán Rodriguez. Árvores isoladas de duas espécies nativasem pastagem de BrachiariadecumbensStapf no cerrado. PasturasTropicales, v.27, p.51-56, 2005.

PACIULLO, Domingos Sávio Campos et al. Influência do sombreamento e do nitrogênio nas características produtivas de duas espécies de capim braquiária. In: CONGRESSO NORDESTINO DE PRODUÇÃO ANIMAL. Anais... Aracajú. 2008

PACIULLO, Domingos Sávio Campos et al. Potencialidades E Desafios De Sistemas Silvipastoris. In: Congresso Brasileiro de Zootecnia, 24, 2014, Vitoria- Es. Anais...Vitoria- Es: Zootec, 2014.

PORFÍRIO DA SILVA, Vanderlei; MAZUCHOWSKI, Jorge Zbigniew. Sistemas silvipastoris: paradigma dos pecuaristas para agregação de renda. Curitiba: EMATER-PR, 1999. 52p. (Série Informação Técnica, 50).

PULINA, Giuseppe et al.Models for estimatingfeedintake in smallruminants. R. Bras. Zootec., v. 42, n. 9, p. 675-690, 2013. 
QUADROS, Danilo Gusmão. Pastagens para Ovinos e Caprinos. In: SIMPOGECO - SIMPÓSIO DO GRUPO DE ESTUDOS DE CAPRINOS E OVINOS 2. Salvador: UFBA. (Material didático). 34p. 2006.

RESTLE, João et al. Influência das taxas de ganho de peso pré-desmame das vacas e do tipo de pastagem no período pós-parto sobre a eficiência biológica de vacas e de bezerros de corte. R. Bras. Zootec., v. 36, n. 4, p. 874-880, 2007.

SANTOS, Andréa Souza. Vulnerabilidadessocioambientaisdiante das mudançasclimáticasprojetadas para o semi-árido da Bahia. 2008. 153p. (Dissertação de mestrado) Centro de DesenvolvimentoSustentável, Universidade de Brasília, Brasília, 2008.

SANTOS, Francielle Rodrigues; SANTOS, Mário Jorge Campos. Sistema silvipastoril com ovinos mantidos em pastejo rotacionado no semi-árido sergipano. ACSA - Agropecuária Científica no SemiÁrido, v.06, n 02, 2010, p. 28 - 31.

SAMARAKOON, SirisenaPannala; WILSON, John Richard; SHELTON, H.Max. Growth, morphology and nutritive value of shaded Stenotaphrumsecundatum, Axonopuscompressus and Pennisetumclandestinum. J.Agr. Sci., Cambridge, v.114, p.161-169, 1990.

VEIGA, Jonas Bastos et al.Sistemassilvipastorisna Amazônia Oriental.Belém: Embrapa Amazônia Oriental, 2000. 62p. (Embrapa Amazônia Oriental. Documentos, 56).

WADT, Paulo Guilherme Salvador. Práticas de conservação do solo e recuperação de áreas degradadas. Rio Branco: Embrapa Acre, 2003. (Embrapa Acre. Documentos, 90).

WILSON, John Richard. Influence of planting four tree species on the yield and soil water status of green panic pasture in sub humid south-east Queensland.Trop. Grass., v. 32, p. 209-220, 1998. 